\title{
PAPO DE HOMEM: RODAS DE CONVERSA SOBRE PRIAPISMO NA DOENÇA FALCIFORME
}

Kayque Neves da Silva ; Evanilda Souza de Santana Carvalho; Heros Aureliano Antunes da Silva Maia; Mateus Andrade Alvaia; Nadja Layane Gomes Santiago

1. Bolsista CNPq, Graduando em Medicina, Universidade Estadual de Feira de Santana, e-mail: kayquesn@hotmail.com

2. Orientador, Departamento de Saúde, Universidade Estadual de Feira de Santana, e-mail: evasscarvalho@yahoo.com.br

3. Bolsista CNPq, Graduando em Medicina, Universidade Estadual de Feira de Santana, e-mail: herosmaia@hotmail.com

4. Bolsista CNPq, Graduando em Medicina, Universidade Estadual de Feira de Santana, e-mail: mateus_alvaia@hotmail.com

5. Bolsista FAPESB, Graduanda em Medicina, Universidade Estadual de Feira de Santana, e-mail: nadjalayane@hotmail.com

PALAVRAS-CHAVE: Doença falciforme, Estigma, Priapismo.

\section{INTRODUÇÃO}

O termo priapismo se refere a ereção persistente, não acompanhada de desejo sexual ou estimulação, que dura mais de 6 horas, envolvendo tipicamente somente o corpo cavernoso do pênis (KEOGHANE et al, 2002). Tais autores acrescentam ainda que essa condição caracteriza uma emergência urológica, visto que a disfunção erétil é uma sequela comum do manejo inapropriado.

O priapismo é uma ocorrência frequente no sexo masculino com anemia falciforme (KATO, 2012). A probabilidade do desenvolvimento do priapismo em homens com DF é de 42 em 100 (BIVALACQUA, 2009).

Essa manifestação fenotípica da DF pode causar impotência persistente, disfunção erétil e problemas na vida sexual dos pacientes, uma vez que os indivíduos afetados temem a ocorrência de um episódio de ereção dolorosa no andamento da atividade sexual normal, que é a causa mais comum de episódios de priapismo após a puberdade do paciente (JESUS, 2009).

Em estudo sobre a experiência do priapismo em homens com DF (RIOS et al, 2013) foi reportado que essa complicação induz a sentimentos de humilhação, vergonha e medo nos cenários de cuidado.

Assim, com base no exposto este estudo buscoudiscutir o priapismo entre os homens com DF, conhecer as ideias, mitos e tabus sobre o priapismo partilhados pelos homens com DF e elaborar material educativo sobre o priapismo e medidas de cuidados

\section{MATERIAL E MÉTODOS OU METODOLOGIA (ou equivalente)}

Nesse estudo foi utilizado a pesquisa qualitativa, que se destina ao estudo da história, das relações, das representações, das crenças, das percepções e das opiniões (MINAYO, 2010).

O presente estudo foi desenvolvido no Centro de Referência à Doença Falciforme em Feira de Santana, a escolha dessa unidade se deveu ao fato de nesse cenário ocorrer o atendimento de pessoas com DF e suas famílias para atenção à saúde nos diversos níveis de atenção. Também destaca-se que após a oferta de atendimento com Urologista e discentes de medicina vinculados ao projeto, tem se observado uma maior busca de serviços da unidade por parte dos homens, para tratar de problemas relacionados à sexualidade.

Participou homens com doença falciforme, a partir dos 18 anos. Não foram estabelecidos critérios de exclusão por considerar que a participação nas Rodas de Conversa se traduz em oportunidade de aprendizado de homens que também não 
tiveram a experiência do priapismo e que podem tanto assimilar quanto difundir o conhecimento e prevenir complicações.

Para a produção dos dados foram realizadas três encontros com rodas de conversa. Segundo Afonso e Abade (2008) rodas de conversa constituem uma metodologia participativa que pode ser utilizada em diversos contextos, tais como escolas, postos de saúde e associações comunitárias.

$1^{\circ}$ Encontro: Explorar o conhecimento que o grupo tem acerca do priapismo. Levantar as dúvidas que deverão ser registradas pelo moderador;

$2^{\circ}$ Escolha de um tipo de material educativo a ser produzido que atenda aos quesitos: interesse do grupo, adequação ao tema escolhido e viabilidade;

$3^{\circ}$ Confecção do material escolhido: definição de roteiro. Divulgação do material junto a outros grupos, a partir da qual terá início outro grupo.

Para análise dos depoimentos foi utilizado o método de Análise de Conteúdo Temático. Este tipo de análise é organizado em três fases, 1) Pré-análise, a partir de leitura flutuante e escolha do material de analise 2) Exploração do material com definição de categorias e a identificação das unidades de registro e das unidades de contexto; 3) Tratamento dos resultados que consiste na inferência e interpretação dos resultados, e interpretações inferenciais (Bardin, 2006).

\section{RESULTADOS E/OU DISCUSSÃO (ou Análise e discussão dos resultados)}

Participaram três estudantes de medicina do sexo masculino e 7 homens com doença falciforme associados à Associação Feirense de Pessoas com Doença Falciforme AFADFAL. Foram realizados três encontros os quais serão detalhados a seguir.

No primeiro encontro foi discutido abertamente sobre vários temas que circulam o priapismo, o convite para participar das Rodas de conversa sobre priapismo suscitou muito interesse por parte dos homens. Destes, 4 já haviam experienciado priapismo na juventude ou vida adulta e indicaram dificuldades com a função erétil, atribuída aos sucessivos eventos de priapismo. Face a essa consequência do priapismo os participantes adotam estratégias que variam desde o uso de medicamentos $\mathrm{e}$ formulações que prometem devolver a ereção, uso de cremes ou investir mais tempo nas preliminares para enfrentar a limitação e tentar exercer a penetração no ato sexual, quanto podem desistir e aceitar a situação da disfunção erétil como definitiva e sem solução.

Enquanto os estudos revisados apontam por uma elevada busca por ajuda medica, dentre os entrevistados a vergonha antecipada limita os homens a acessar serviços especializados, em geral procuram primeiro cansar fisicamente o corpo submetendo-se a exercícios como caminhada, se submetem a banhos prolongados buscando relaxamento do pênis, ou procuram se aconselhar com um amigo mais próximo, em segundo da família e em último caso do profissional de saúde. Tudo isso leva a um retardo na busca por atendimento de emergência e consequente também adiará os procedimentos invasivos requeridos, comprometendo assim na capacidade erétil do membro.

As experiências nas unidades de emergência foram recordadas como sendo negativas e constrangedoras, marcadas pela superexposição do corpo e destacada vergonha dos homens frente as cuidadoras do sexo feminino (sejam medicas, enfermeiras ou técnicas de enfermagem, além de estudantes/estagiarias).

No segundo momento após recordarem um pouco dos relatos das experiências ocorrido no primeiro encontro, foi discutido sobre que tipo de material poderia ser confeccionado para que esse tema fosse abordado de uma forma que todas as pessoas compreendessem o tema independente da faixa etária. Foi quase um consenso que a melhor forma de passar esse conteúdo era a partir de uma história em quadrinhos, mostrando o primeiro episódio de priapismo em um adolescente e a experiência de contar para os familiares e 
procurar ajuda, com o tipo de material escolhido e o enredo a ser traçado foi encerrado o segundo encontro.

O terceiro encontro, já com as ideias em mãos, os participantes realizaram um esboço dos desenhos que representassem o tema de interesse, e na sequência foi decidido sobre a quantidade de páginas que teria o material e escrito o conteúdo pretendido como enredo da história em quadros.

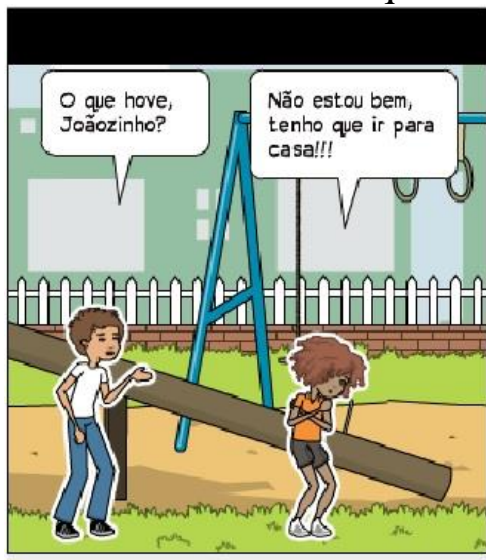

Um certo dia, Joãozinho sentiu algo estranho enquanto estava brincando, percebeu que seu pênis estava endurecido e não passava então correu envergonhado para casa.

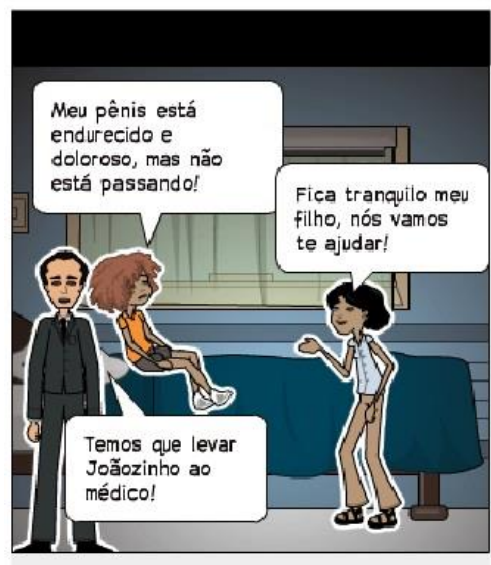

Joãozinho contou a sua familia o que estava acontecendo, eles acolheram Joãozinho da melhor forma possivel e o levou ao médico.

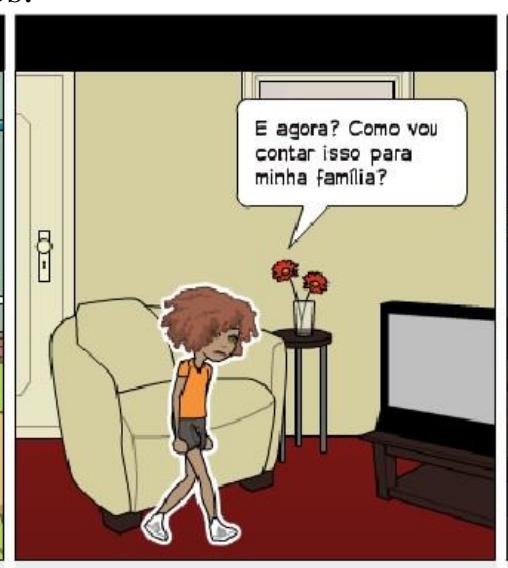

Chegando lá foi para seu quarto e ficou escondido, sem saber o que fazer.

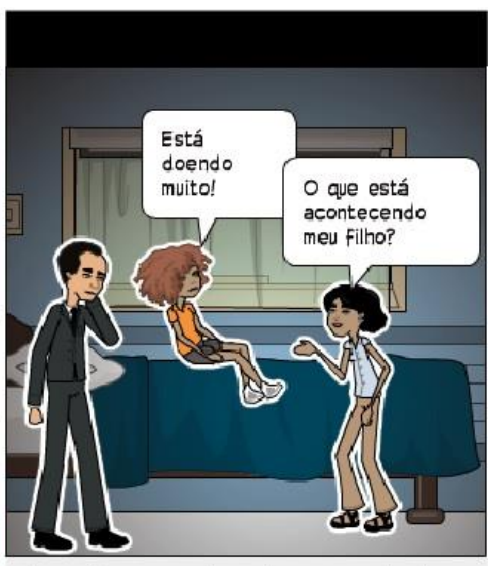

Sua mãe e seu pai perceberam que havia algo errado e foram ver o que era. Chegando no quarto eles perguntaram a Joãozinho 0 que tinha acontecido.

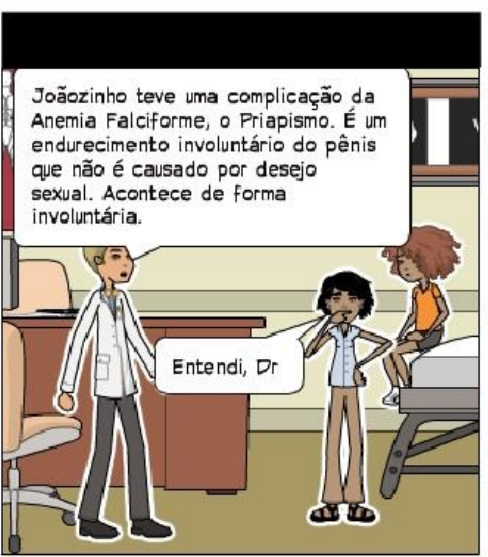

No consultório.

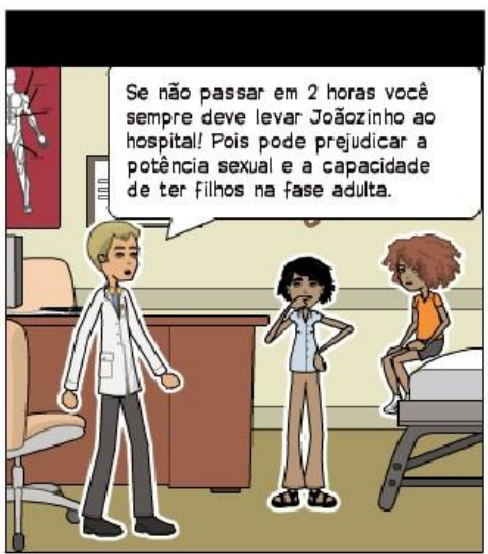

No consultório

Primeira página da história em quadros.

\section{CONSIDERAÇÕES FINAIS (ou Conclusão)}

Este estudo buscou discutir o priapismo entre os homens com DF, conhecer as ideias, mitos e tabus sobre o priapismo partilhados pelos homens com DF e elaborar um material educativo sobre o priapismo e medidas de cuidados.

Os participantes se mostraram muito motivados a integrarem a roda, reafirmando a importância de ter um espaço para o diálogo sobre os seus problemas, de forma relaxada e fora da consulta com o profissional de saúde.

Durante as rodas de conversa foi falado sobre as experiências vividas por cada integrante que já teve a complicação, esses relatos caminharam de forma livre e espontânea, para uma melhor integração e participação de todo o grupo. Dos temas discutidos os mais abordados foram como ocorreram os primeiros episódios e a dificuldade em buscar ajuda, tanto familiar como profissional, o sentimento de vergonha que a problemática causa em todos eles. Também foi destacado a vergonha diante da exposição e constrangimento vivenciado nas unidades de atendimento de emergências. 
Outro tema discutido foi a impotência sexual que pode ocorrer após essa complicação, alguns membros relataram como eles convivem com essa complicação da DF e as estratégias que adotaram para aceitar e conviver com essa dificuldade nas suas vidas.

\section{REFERÊNCIAS}

KEOGHANE, SR, SUlliVAN, ME, MILlER, MAW. The aetiology, pathogenesis and management of priapism. BJU International. 2002;90:149-54

KATO, GREGORY J. Priapism in Sickle-Cell Disease:

A Hematologist's Perspective. The journal of sexual medicine, v. 9, n. 1, p. 70-78, 2012.

BIVALACQUA,

TRINITY

$\mathrm{J}$.

et

al. Establishment of a transgenic sickle-cell mouse model to study the pathophysiology of priapism. The journal of sexual medicine, v. 6, n. 9, p. 2494-2504, 2009.

JESUS, LISIEUXEYER DE; DEKERMACHER, SAMUEL. Priapismo em crianças: revisão de fisiopatologia e tratamento:[revisão]. J Pediatr, p. 194-200, 2009

RIOS, T. A. O., RODRIGUES, C. S. S., XAVIER, A. S. G., CARVALHO, E. S. S., et al. Significado do priapismo para homens com doença falciforme. $3^{\circ}$ seminário internacional sobre saúde da população negra. 2013, Universidade Estadual de Feira de Santana

MINAYO, M.C. de S. (2010). O desafio do conhecimento: Pesquisa Qualitativa em Saúde. (12 edição). São Paulo: Hucitec-Abrasco

AFONSO, M. L.; ABADE, F. L. Para reinventar as rodas: rodas de conversa em direitoshumanos. Belo Horizonte: RECIMAM, 2008

BARDIN, L. (2006). Análise de conteúdo (L. de A. Rego \& A. Pinheiro, Trads.). Lisboa: Edições 70. (Obra original publicada em 1977) 